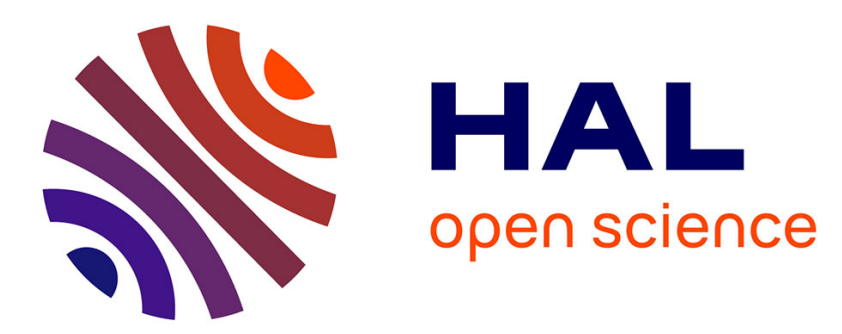

\title{
Composition variation of illite-vermiculite smectite mixed-layer minerals in a bentonite bed from Charente (France)
}

Alain Meunier, Bruno Lanson, Bruce Velde

\section{- To cite this version:}

Alain Meunier, Bruno Lanson, Bruce Velde. Composition variation of illite-vermiculite smectite mixedlayer minerals in a bentonite bed from Charente (France). Clay Minerals, 2004, 39, pp.317-332. 10.1180/0009855043930137 . hal-00193936

\section{HAL Id: hal-00193936 \\ https://hal.science/hal-00193936}

Submitted on 5 Dec 2007

HAL is a multi-disciplinary open access archive for the deposit and dissemination of scientific research documents, whether they are published or not. The documents may come from teaching and research institutions in France or abroad, or from public or private research centers.
L'archive ouverte pluridisciplinaire HAL, est destinée au dépôt et à la diffusion de documents scientifiques de niveau recherche, publiés ou non, émanant des établissements d'enseignement et de recherche français ou étrangers, des laboratoires publics ou privés. 


\section{COMPOSITION VARIATION OF ILLITE-VERMICULITE- SMECTITE MIXED-LAYER MINERALS IN A BENTONITE BED FROM CHARENTE (FRANCE)}

Alain MEUNIER ${ }^{1}$, Bruno LANSON ${ }^{2}$ and Bruce VELDE ${ }^{3}$

1 HYDRASA UMR 6532, CNRS-University of Poitiers, 40 av. Recteur Pineau, 86022 Poitiers Cedex, France

2 LGIT - Maison des GéoSciences, CNRS - University Joseph Fourier, PO Box 53, 38041 Grenoble Cedex 9, France

3 Laboratoire de Géologie, E.N.S., 24 rue Lhomond, 75231 Paris Cedex 05, France

Running title: Mineralogical heterogeneity of an unaltered bentonite bed

KEY WORDS: bentonite, Charentes, decomposition, high-charge smectite, hydration properties, mixed layer minerals.

Correspondence should be sent to: Alain MEUNIER

HYDRASA UMR 6532 CNRS University of Poitiers, 40 av. Recteur Pineau, 86022 Poitiers Cedex, France

e-mail:alain.meunier@hydrasa.univ-poitiers.fr 


\begin{abstract}
Mineralogical and chemical variations were studied in the upper half of a 1 $m$ thick discontinuous bentonite bed interlaminated in the Lower Cenomanian sedimentary formations of the northern Aquitaine basin (France). X-ray diffraction patterns obtained from the $<2 \mu \mathrm{m}$ fraction in the Ca and K-saturated states were decomposed and compared to those calculated from decomposition parameters. They revealed the presence of two highly expandable illiteexpandable (I-Exp) mixed-layer minerals (MLMs). Relative proportions of the two MLMs steadily evolve with depth leading to the decrease of the cation exchange capacity and of the $(\mathrm{Na}+\mathrm{Ca})$ content towards the center of the bentonite bed. However, the system is essentially isochemical and $\mathrm{Mg}, \mathrm{Al}, \mathrm{Si}, \mathrm{K}$ and $\mathrm{Fe}$ are roughly constant in the bulk samples. It is thought that the mineralogical zonation results from the initial stages of the smectite formation in an ash layer.
\end{abstract}

In the Ca-saturated state, the expandable component of these MLMs was for the most part homogeneous with the presence of 2 sheets of ethylene glycol molecules in the interlayer. However, the heterogeneous hydration behaviour of these expandable layers was enhanced by the potassium saturation test. From this test, the presence of three layer types with contrasting layer charge was evidenced from their contrasting swelling abilities. The $\mathrm{C}_{12}$-alkylammonium saturation test applied to samples in which the octahedral charge had previously been neutralized (Hofmann-Klemen treatment) showed that the tetrahedral charge is located on specific layers. These layers are responsible for the heterogeneous hydration behaviour. Low-charge smectite layers are mostly octahedrally substituted, 
whereas for intermediate- and high charge layers this montmorillonitic charge is complemented by additional tetrahedral substitutions ( 0.30 and $0.35-0.40$ charge per $\mathrm{O}_{10}(\mathrm{OH})_{2}$, respectively).

\section{INTRODUCTION}

It has been established in numerous studies that smectitic bentonite beds tend to alter to illite by diffusion processes at their contacts with encompassing rocks and sediments (Foscolos \& Kodama, 1974; Velde \& Brusewitz, 1978; Hoffman \& Hower, 1979; Huff \& Türkmenoglu, 1981; Altaner et al., 1984). These sedimentary units form K-bentonites. The rate at which this diffusioncontrolled reaction occurs has been estimated by Altaner (1985). The most remarkable observation is the increase of the potassium content in the essentially monomineralic bed towards its outer edge. In most cases, illite-smectite (I-S) mixed-layer minerals (MLMs) are smectite-rich in the interior of the bentonite bed and have a higher illite content at the edge. Such occurrences have been assumed to represent simple smectite-to-illite reaction series which appear to differ in their kinetics of transformation when compared to detrital shales (Sucha et al., 1993).

Implicit in such a mineralogical sequence is the initial conversion of the acidic volcanic ash into a monomineralic material of essentially pure smectite composition. In this preliminary process, a chemical exchange with the exterior of the ash bed is necessary to transform the original volcanic rock into smectite through a non-isochemical process. It is always assumed that the initial ash bed transformation gives a homogeneous smectite layer (Altaner, 1985). However, 
since the initial phases of the ash-to-clay transformation imply an exchange of several elements, there is little reason to exclude an initial composition gradient during the smectite formation process.

The object of the present investigation is to assess the mineralogical homogeneity of a Cretaceous bentonite bed which has experienced little burial diagenesis leading to clay mineral transformation. The unit has experienced only shallow burial and no tectonic effect during its 120 Ma existence (Meunier et al., 1999). Here, we expect to see the initial stages of diffusion and smectite formation before illitization (Meunier et al., 2000).

\section{MATERIALS AND METHODS}

Sample location and existing data

The investigated bentonite bed is discontinuously interlaminated in the Lower Cenomanian sedimentary formations from the northern Aquitaine basin (Fig. 1). It belongs to the A unit in the Lower Cretaceous stratigraphic sequence (Meunier et al., 1999). This bed is $1 \mathrm{~m}$ thick in the sampling area: a quarry near Archingeay (Charentes, France). There, it is interlaminated between two unconsolidated sand deposits (Fig. 1). For this study, 5 samples were taken out at regular $10 \mathrm{~cm}$ intervals and indexed $\mathrm{A}, \mathrm{B}, \mathrm{C}, \mathrm{D}$ and $\mathrm{E}$ from top to bottom in a vertical profile. 
Analytical procedures

All samples were gently crushed in an agate mortar. The powders were then ultrasonically dispersed in distilled water and the $<2 \mu \mathrm{m}$ fraction was separated from the suspension using standard sedimentation procedures. Oriented preparations of a Ca-saturated $<2 \mu \mathrm{m}$ fraction were analyzed by means of X-ray diffraction (XRD) in the air-dried state (AD), and after ethylene-glycol solvation (EG). Additional analyses were carried out from EG solvated samples after Ksaturation, and after Li-exchange and heating to $300^{\circ} \mathrm{C}$ (Li-300; Hofmann \& Klemen, 1950). The contribution of tetrahedral substitutions to the total layer charge was estimated by comparing XRD patterns obtained for each sample after saturation with $\mathrm{C}_{12}$-alkylammonium (Olis et al., 1990) of the original sample and of the Li-300 sample in which the octahedral charge has been neutralized. XRD patterns were recorded using a Philips ${ }^{\circledR}$ PW 1730 diffractometer (Ni-filtered Cu$\mathrm{K} \alpha$ radiation generated at $40 \mathrm{kV}$ and $40 \mathrm{~mA}$ ), equipped with a stepping motor drive in the goniometer (SOCABIM DACO system). A Co-Ka radiation generated at $40 \mathrm{kV}$ and $40 \mathrm{~mA}$ has been used to analyse the samples saturated with $\mathrm{C}_{12}$-alkylammonium ions. The usual analytical conditions were $2-35^{\circ} 2 \theta$ as a data collection range, $0.025^{\circ} 2 \theta$ as scanning step size and 6 s per step as counting time.

The smectite samples were chemically analyzed for major elements using ICP-AES (experimental errors are $<1 \%$ for $\mathrm{SiO}_{2}, \mathrm{Al}_{2} \mathrm{O}_{3}, \mathrm{Fe}_{2} \mathrm{O}_{3}, \mathrm{MgO} ;<2 \%$ for $\mathrm{TiO}_{2}, \mathrm{MnO}, \mathrm{CaO}, \mathrm{K}_{2} \mathrm{O}, \mathrm{Na}_{2} \mathrm{O}$ ). Cation exchange capacity (CEC) was obtained by saturation with $\mathrm{Mg}^{2+}$, the excess of $\mathrm{Mg}$ salt being carefully washed out with ethanol. The $\mathrm{Mg}^{2+}$ was then displaced by $\mathrm{NH}_{4}{ }^{+}$and analyzed by atomic absorption 
spectroscopy (AAS) in the exchange solution (experimental error $<1 \%$ for CEC $>$ $\left.60 \mathrm{cmol} \mathrm{kg}^{-1}\right)$.

Methods for the interpretation of XRD patterns

Most identification methods routinely used to determine the composition of I-S MLMs rely on the position of diffraction maxima, on relative positions of maxima, on intensity ratios between these bands, or on peak/background intensity ratios (Srodon, 1981; Velde et al., 1986; Watanabe, 1988; Inoue et al., 1989; Esposito \& Whitney, 1995 among many others). These parameters are first measured on experimental XRD patterns and then compared with values determined from calculated patterns. However, one may note that all these methods rely on two main hypotheses: (i) the expandable (inter)layers are assumed to be homogeneous as all calculations are performed for 2 components: illite and expandable layers (I-Exp). As a consequence, none of these identification methods allows the description of 3 component systems such as the illite-smectite-vermiculite (I-S-V) MLMs reported (e.g.) by Drits et al. (1997) in which the expandable layers have an heterogeneous behavior after hydration and/or EG solvation and are differentiated as smectite (S-type, fully expandable layers with 2 sheets of $\mathrm{H}_{2} \mathrm{O}$ or EG molecules) and vermiculite (V-type, partly expandable layers with only 1 sheet of $\mathrm{H}_{2} \mathrm{O}$ or EG molecules; see Meunier et al., 2000 for detailed definitions); (ii) samples are most often assumed to be monomineralic and these methods may rarely be satisfactorily applied to samples containing several MLMs. 
The errors introduced by these methods when applied to 3-component systems may be illustrated by applying some of them to XRD patterns calculated for 20:80 I-Exp MLMs in which the swelling behavior of the expandable layers is heterogeneous (Fig. 2). Initially, one may note in Table 1 that the identification results obtained for a simple two-component system ( $0 \% \mathrm{~V}$ in I-S) strongly depend on the identification method used as estimates range from 90 to $72 \%$ smectite. In addition, the identification results also depend on the swelling behavior of the expandable layers. Some of the identification methods used are not applicable if V-type layers are present in I-Exp MLMs, whereas others may still be applied but provide different results as a function of the relative proportions of S- and V-type layers in the stacking sequences, increasing the range for the estimated smectite content to $95-54 \%$ (Table 1).

Because the presence of expandable layers with contrasting swelling behaviors may also be encountered in bentonites (Calarge et al., 2003) a three step process was adopted to identify the MLMs present in our bentonite samples: first, decomposition of the diffraction peaks into Gaussian and Lorentzian elementary contributions was performed using the DECOMPXR program (Lanson, 1997). This decomposition procedure was carried out on 00l peaks from XRD patterns recorded after different sample treatments (Ca-AD, Ca-EG, K-EG of peaks at 1520, 8-12 and 2-12 ${ }^{\circ} 2 \theta \mathrm{Cu}-\mathrm{K} \alpha$ angular ranges respectively). Special attention was paid to the first steps of the procedure, and specifically to background stripping. As recommended by Lanson (1997) background was assumed to be linear whenever possible $\left(2 \theta \geq \sim 8^{\circ}\right)$, and interpolated assuming a Lorentz-factor like shape in low angle regions. The decomposition was performed by obtaining a satisfactory fit to the experimental data using a minimum number of elementary 
contributions. However, these elementary contributions are related to specific (sub-)populations of crystals which contribute to the scattered intensity over the whole angular range whatever the physical and chemical pre-treatment. As a consequence, the preliminary identification allowed us to introduce additional constraints on the number of elementary contributions that can be used in the analysis of smectite patterns following the different treatments. In the present case, constraints were not only derived from the processing of peaks from the same XRD pattern but also from the analysis of peaks from patterns of the same sample recorded in different conditions (cation exchange, EG solvation, etc...) as recommended by Drits et al. (1997) and Sakharov et al. (1999) for their multispecimen approach.

The decomposition allowed an objective description of peak profile modification with "depth" in the bentonite bed. Second, the position, intensity and FWHM parameters of these elementary contributions were used for a preliminary individual identification of each "clay phase” (type of MLM; \%smectite) by comparison with calculated patterns. XRD patterns were calculated using the softwares from Plançon \& Drits (2000; http://www.univorleans.fr/ESEM/plancon) which allow the calculation of three-component MLMs without restrictions on the nature of the different layer types or on the junction probabilities. All parameters necessary for such calculations (atomic positions, dspacings) were set as recommended by Moore \& Reynolds (1989) except for the basal spacing of smectite layers with only one sheet of EG molecules which was set to $13.5 \AA$. Finally, the validity of this preliminary identification was checked by the calculation of the complete XRD profile corresponding to the various elementary contributions identified. 


\section{RESULTS}

\section{Chemical composition}

The chemical compositions of the $<2 \mu \mathrm{m}$ size fraction from the five samples (Table 2) are relatively homogeneous in spite of some erratic variations related to impurities. The $\mathrm{SiO}_{2}$ content varies because of the presence of microcrystalline quartz (e.g. sample D). The amounts of $\mathrm{CaO}$ and $\mathrm{Na}_{2} \mathrm{O}$ as well as the CEC decrease regularly with increasing depth (Fig. 3) while the $\mathrm{K}_{2} \mathrm{O}$ content remains roughly constant throughout the bed.

XRD analyses

Air-dried and glycol solvated states (Ca-saturated). According to Inoue et al. (1989), the low background intensity on the low angle side of the smectite 001 reflection suggests a high smectite content in the investigated clays (Figs 4, 5). However, on the same experimental pattern the significant asymmetry of the smectite 002 reflection ( 8.55 $\AA$ ) towards lower angles (Fig. 4) suggests the presence of several expandable phases. If this asymmetry was due to contrasting swelling ability of expandable layers, a significant shift of the $\sim 17.0 \AA$ reflection would also be observed as illustrated on Figure 2. The presence of these highly expandable MLMs is also evidenced by the asymmetry of the smectite 003

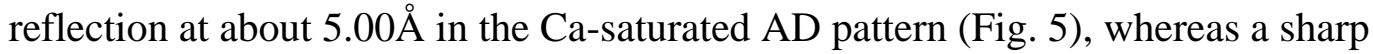
symmetrical peak is usually observed when essentially expandable phases are contributing to the diffracted intensity even if the hydration state of the expandable layers is not homogeneous. The above peak asymmetries seem to 
evolve with depth in the sampled sequence (Figs. 4, 5) to indicate a change in the composition of MLMs, which could be related to the CEC evolution with depth in the sampled sequence.

To assess the possible presence of such different MLMs, and to obtain an objective description of their diffraction behaviour, we have decomposed the peaks mentioned above. It was first assumed that all mixed-layered components, and illite, have a unique contribution in each of these angular ranges. The validity of this assumption was checked in the identification step by the calculation of the whole experimental XRD profile. All experimental XRD patterns were successfully fitted with three contributions. The sharper contribution (FWHM = $0.2-0.5^{\circ} 2 \theta$ ) likely corresponds to illite and/or detrital mica whereas the other two phases exhibit broader reflections of variable intensities and positions (Tables 3, 4; Figs. 6, 7). For the Ca-EG diffraction pattern, the positions of these two contributions range from 8.45-8.52 $\AA$ (major contribution) and from 8.72-9.22 $\AA$, respectively (Table 3; Fig. 6). These two mixed-layered structures contribute to the Ca-AD XRD pattern at 4.99-5.03 $\AA$, and 5.03-5.07 $\AA$, respectively (Table 4; Fig. 7). These contributions were both attributed to I-Exp MLMs.

To check the validity of the assumed nature of phases contributing to the diffracted intensity, experimental XRD patterns were compared to profiles calculated with the programs developed by Plançon \& Drits (2000). It was possible to obtain a satisfactory fit to the experimental data by assuming, in agreement with the decomposition results, the presence of two MLMs, in addition to an illite-rich phase (Fig. 8). The first mixed-layered structure (I-Exp 1 ) corresponds to a highly expandable, disordered (R=0) I-Exp MLM (peak at $\sim 8.5 \AA$ on the Ca-EG pattern) whereas the second MLM (I-Exp $)$ is less 
expandable (peak at $\sim 8.9 \AA$ on the Ca-EG pattern). In these two MLMs, the swelling behaviour of the expandable component is heterogeneous as the compositions of I-Exp 1 and I-Exp 2 are respectively 70:20:10 and 40:30:30 (S:V:I ratios). Because these two MLMs were systematically identified after different sample treatments (see below), no attempt was made to try to describe these two MLMs as a unique MLM.

One may note that the decomposition of Ca-AD XRD patterns leads to intensity ratios between the different contributions that are similar for all samples. On the contrary, the contribution of illite and/or detrital mica is much enhanced on the Ca-EG XRD patterns of samples D and E, as compared to samples A-C, whereas the contribution of $\mathrm{I}_{\mathrm{Exp}} \mathrm{Ex}_{1}$ is decreased for the former samples. This is likely due to the increased contribution of illite crystallites with small coherent scattering domain sizes (CSDS) for samples D and E as shown by the increased breadth of the $\sim 10.0 \AA$ diffraction maximum in the Ca-EG XRD pattern (Fig. 6). On the Ca-AD XRD patterns, the breadth of the diffraction maximum attributed to the illite and/or detrital mica is systematically low (Fig. 7). It is thus likely that this peak represents the whole contribution for illite and/or detrital mica in samples A-C, whereas it accounts only for the larger crystallites in samples D and E. In the Ca-EG state (Fig. 7) illite crystallites with a smaller CSDS present in samples D and E are included in the I-Exp1 contribution which is thus enhanced as compared to the Ca-AD state (Fig. 6).

Identification of smectite layer components

Hofmann-Klemen treatment. Following the Hofmann-Klemen treatment, all samples show two broad bands at about $17 \AA$ and $9.6 \AA$ (Fig. 9) corresponding to 
domains containing mostly expanded beidellitic layers and collapsed montmorillonitic layers, respectively. However, the high saddle/peak ratio observed for the $17 \AA$ peak is reminiscent of the interstratification effects described by Inoue et al. (1989) for I-S MLMs and possibly indicates the coexistence (interstratification) of collapsed and expanded layers in the same "crystals". From their similar respective intensities, and considering the greater contribution of the structure and Lorentz-polarization factors to intensity at low angles, the relative abundance of the $17 \AA$ component appears to be lower than that of the $9.60 \AA$ one.

K-saturated ethylene glycol solvated state. XRD patterns obtained from Ksaturated samples in the EG state all exhibit a broad maximum in the $17 \AA$ region (Fig. 10). If compared to the $17 \AA$ band in the Ca-EG sample (Fig. 4), the width of this $17 \AA$ band is considerably increased and its position for A and B samples is shifted towards lower d-values. This may indicate that the average CSDS is lower in the K-EG state, but a significant decrease of the CSDS would induce a strong shift of the position towards higher d-values. Rather this increased peak width is likely related to the presence of layers that are fully expandable after Casaturation (S-type) and only partly expandable (V-type) or even collapsed to $10 \AA$ when K-saturated. As a result, the peak position shifts towards lower d-values (from 17.06 to $16.12 \AA$ for sample A in the in the Ca-EG and K-EG states, respectively). Since the position shift decreases A to E, the relative proportion of such partly expandable layers likely decreases with depth. The K-saturation outlines the charge heterogeneity of expandable layers in the main smectite-rich IExp 1 MLM. 
The decomposition of the diffraction profile over 2-12 ${ }^{\circ} 2 \theta$ gives a satisfying fit with three diffraction bands (Fig. 11). The overwhelming broad (2.28>FWHM>1.86) 16.22-17.03 $\AA$ band represents the sole contribution of the I$\operatorname{Exp}_{1}$ phase identified in Ca-saturated samples. The sharp $(0.21>\mathrm{FWHM}>0.18)$ contribution at $9.95-10.07 \AA$ is related to the illite/mica phase, whereas the broad (2.32 $>$ FWHM $>1.87) 10.17-9.82 \AA$ contribution is likely related to the I-Exp2 mixed-layer structure. The intensity of the latter contribution is extremely low as compared to that attributed to I-Exp 1 . This contrast arises most likely from their contrasting structure factors over this angular range rather than from their relative proportions. In spite of this low intensity the I-Exp 2 contribution likely integrates the second order of the I-Exp ${ }_{1}$ contribution. This is supported by the variability of the I-Exp 2 peak position, and more especially by its shift on the high angle side of the illite contribution which can hardly be accounted for otherwise.

$C_{12}$-alkylammonium saturation state. This study was performed after neutralizing the octahedral charge with the Hofmann-Klemen treatment, which produced collapsed and expandable layers, possibly interstratified (see Hofmann-Klemen paragraph). Then, the remaining tetrahedral charge has been investigated using the $\mathrm{C}_{12}$-alkylammonium saturation procedure to identify high- and low-charge layers (2 or 1 alkylammonium layers respectively). Resulting XRD patterns show an intense peak at about $13.6 \AA$ which is typical of low-charge layers, which intercalate only one sheet of alkylammonium cations (Lagaly \& Weiss, 1969). On the low angle side of this broad maximum, a shoulder is visible at $\sim 17.2 \AA$ indicating the presence of high-charge layers with 2 sheets of alkylammonium cations. A weak $10 \AA$ peak is also visible on these patterns (Fig. 12). After 
decomposition, the broad $13.6 \AA$ peak is shown to include the contributions from three different populations of crystals which scatter X-rays coherently (Fig. 13). The main 13.5-13.6 $\AA$ peak is typical of low-charge layers having one sheet of alkylammonium cations whereas the 17.1-16.5 $\AA$ and the 11.9-11.5 $\AA$ peaks likely represent the contributions of domains in which layers with contrasting alkylammonium contents are interstratified. The first of these contributions (MLM1) include layers having 2 and 1 sheets of alkylammonium cations (high and low tetrahedral charge respectively) whereas the other contribution (MLM2) include layers with 1 and 0 alkylammonium sheet (low and no tetrahedral charge respectively).

\section{DISCUSSION}

Decomposition of the XRD patterns obtained from our samples after different treatments indicates the systematic presence of two (I-Exp) MLMs whose structural variability contributes to a general change in XRD profiles. The following discussion will first focus on the characterization of layer charge heterogeneity (amount and location), and then try to relate the observed evolution of this heterogeneity to the main trends derived from bulk chemical analysis of the clay fraction.

\section{Layer charge heterogeneity}

From the comparison of XRD patterns obtained from Ca-EG and K-EG samples, it is possible to hypothesize the coexistence of expandable layers having 
contrasting charges and hydration properties. The $\mathrm{K}^{+}$-for- $\mathrm{Ca}^{2+}$ exchange increases the number of partly or completely collapsed layers (13 and $10 \AA$, respectively) in the I-Exp MLMs after EG solvation. For the most expandable I-Exp 1 MLM, this induces a shift of the $17 \AA$ peak towards lower d-spacing values. In our series of samples, the peak position shifts from 16.22 (sample A) to $17.02 \AA$ (sample E) with depth (Fig. 14) indicating that the proportion of partly or completely collapsed layers in I-Exp 1 increases from E to A, i.e., towards the outside of the bentonite bed.

From the variation of layer expandability as a function of the interlayer cation, one can define at least three types of expandable layers in the studied samples: i) low-charge smectite layers that accept 2 sheets of EG molecules ( $\mathrm{d}_{001} \sim 17 \AA$ ) in both Ca- and K-saturated states; ii) intermediate-charge smectite layers accepting 2 sheets of EG molecules if Ca-saturated but only one ( $\mathrm{d}_{001} \sim 13 \AA$ ) when K-saturated; iii) high-charge layers (vermiculite) that accept 1 sheet of EG molecules when Ca-saturated and are collapsed ( $\left.\mathrm{d}_{001} \sim 10 \AA \AA\right)$ when Ksaturated.

From the presence of domains containing mostly expanded beidellitic layers and collapsed montmorillonitic layers after the Hofmann-Klemen treatment, it is possible to evaluate the relative contributions of octahedral and tetrahedral substitutions to the total layer charge evidenced by Cuadros \& Altaner (1998) in smectitic minerals from bentonite deposits. First of all, one may note the much greater contribution of octahedral substitutions as demonstrated by the similar intensities of the 9.6 and $17 \AA$ peaks observed on XRD patterns recorded after the Hofmann-Klemen treatment (Fig. 9). As a consequence, expandability possibly depends on the amount of beidellitic substitutions. The $\mathrm{C}_{12}$-alkylammonium 
saturation of samples previously submitted to the Hofmann-Klemen treatment to neutralize their octahedral charge allows one to analyze further this beidellitic charge.

Decomposition of these XRD patterns shows that the $13.6 \AA$ band (1 sheet of alkylammonium cations) is the most intense, indicating that, in most of the layers with tetrahedral substitutions, these represent only about 0.30 charge per $\mathrm{O}_{10}(\mathrm{OH})_{2}$ (Olis et al., 1990). The presence of the $16.5-17.1 \AA$ shoulder (2 sheets of alkylammonium cations) shows that some expandable layers present a higher tetrahedral charge (0.35 to 0.40 per $\mathrm{O}_{10}(\mathrm{OH})_{2}$ ). The amounts of $\mathrm{Al}_{2} \mathrm{O}_{3}$ and $\mathrm{MgO}$ in the $<2 \mu \mathrm{m}$ fraction should vary together with the proportion of less expandable layers. This is not clearly the case (see Table 1) probably because the expected composition variations are too small to be detected by such averaging bulk chemical analyses. The distribution of tetrahedral charge may be responsible for the heterogeneous expansion behaviour observed in intermediate and high-charge layers after K-saturation. According to this hypothesis, the location of the layer charge may be assessed for the three layer types defined above. Low-charge smectite layers are mostly octahedrally substituted, whereas for intermediate- and high charge layers this montmorillonitic charge is complemented by additional tetrahedral substitutions ( 0.30 and $0.35-0.40$ charge per $\mathrm{O}_{10}(\mathrm{OH})_{2}$, respectively).

\section{MLM variation throughout the profile}

In the upper part, the composition of the dominant MLM (I-Exp 1 ) changes progressively with depth as shown by the K saturation test and the migration of its

main peak from $17.03 \AA$ (sample E) to $16.22 \AA$ (sample A). This indicates that the 
amount of high-charge layers increases towards the top of the bentonite bed. However the increased charge is not related to a significant change in the K- or Al-content in the bulk composition of the clay-size fraction, suggesting that the studied bentonite bed from Charentes is not a K-bentonite type, where $\mathrm{K}$ and $\mathrm{Al}$ are changed by a post-deposit diffusion process (Cetin \& Huff, 1995).

On the other hand, the observed change in expandability is correlated with the limited but steady CEC increase from the center of the bentonite bed ( 74 cmol. $\left.\mathrm{kg}^{-1}\right)$ towards its edges $\left(\sim 80 \mathrm{cmol} . \mathrm{kg}^{-1}\right.$ - Table 2$)$. This increase correlates with both Ca- and Na-contents (Fig. 3), indicating that the amount of these cations is ruled by the CEC of the expandable layers in the bentonite, and hence by the layer charge heterogeneities. If this reasoning is correct, the mineral changes observed in the layer are due to re-adjustments in an essentially isochemical system, at least concerning the elements $\mathrm{Mg}, \mathrm{Al}, \mathrm{Si}, \mathrm{K}$ and $\mathrm{Fe}$ (no visible changes in chemical compositions presented in Table 1). In this isochemical system, the evolution of hydration ability, expandability and CEC with depth in the bentonite bed must be due to different interlayer charge distributions in expandable layers. For example, for the same layer charge, octahedral and tetrahedral substituted sites may be or not superimposed inside the volume delimited by the upper and lower hexagonal cavities. As a result, the number of highly charged sites may vary: if low, the total charge is spread over the layer surface increasing the CEC and reducing the swelling ability. 


\section{CONCLUSION}

The studied Charentes bentonite bed, although largely smectitic and containing I/S minerals, does not correspond to a K-bentonite occurrence where $\mathrm{K}$ and $\mathrm{Al}$ are exchanged for other elements during a diffusion process which gradually replaces smectite by illite layers in a sequence of I-S minerals. It is possible that the Charentes bentonite corresponds to the initial stage of smectite formation from an ash layer, and that it has not been affected by the processes generating K-bentonites usually described. According to this hypothesis, it is clear that the initial clay mineralogy of the bentonite (smectite) is not homogeneous nor monophase at any one given point. In fact the Charentes bentonite shows mineralogical zoning from the edge toward the center even though its chemistry is not zoned.

ACKNOWLEDGEMENTS: Financial support was provided by UMR 6532 of the CNRS and University of Poitiers (France). The authors thank Drs J. Cuadros and R. Dorhmann for their helpful comments on an early version of this manuscript and Anne-Marie Karpoff for her editorial assistance. 


\section{REFERENCES}

Altaner S.P. (1985) Potassium metasomatism and diffusion in Cretaceous K-bentonites from the Disturbed Belt, north-western Montana and in the Middle Devonian Tioga K-bentonite, eastern U.S.A.. PhD thesis, University of Illinois.

Altaner S.P., Hower J., Whitney G. \& Aronson J.L. (1984) Model for K-bentonite formation: Evidence from zoned K-bentonites in the disturbed belt, Montana. Geology, 12, 412-415.

Calarge L., Lanson B., Meunier A. \& Formoso M.L. (2003) The smectitic minerals in a bentonite deposit from Melo (Uruguay). Clay Minerals , 38, 25-34.

Cetin K. \& Huff W.D. (1995) Layer charge of the expandable component of illite/smectite in K-bentonite as determined by alkylammonium ion exchange. Clays and Clay Minerals, 43, 150-158.

Cuadros J. \& Altaner S.P. (1998) Compositional and structural features of the octahedral sheet in mixed-layer illite/smectite from bentonites. European Journal of Mineralogy, 10, 111-124.

Drits V.A., Lindgreen H., Sakharov B.A. \& Salyn A.S. (1997) Sequence structure transformation of illite-smectite-vermiculite during diagenesis of Upper Jurassic shales, North sea. Clay Minerals, 33, 351-371.

Esposito K.J. \& Whitney G. (1995) Thermal effects of thin igneous intrusions on digenetic reactions in a Tertiary basin of Southwestern Washington. U.S. Geol. Survey Bull. 2085-C, 36pp.

Foscolos A.E. \& Kodama H. (1974) Diagenesis of clay minerals from lower Cretaceous shales of north eastern British Columbia. Clays and Clay Minerals, 22, 319-335. 
Hoffman J. \& Hower J. (1979) Clay mineral assemblages as low grade metamorphic geothermometers: application to the thrust faulted disturbed belt of Montana, U.S.A. Society of Economic Paleontologists and Mineralogists Special Publication, 26, 55-79.

Hofmann U. \& Klemen E. (1950) Lost of exchangeability of lithium ions in bentonite on heating. Zeitschrift für anorganische und allgemeine Chemie, 262, 95-99.

Huff W.D. \& Türkmenoglu A.G. (1981) Chemical characteristics of Ordovician Kbentonites along the Cincinnati Arch. Clays and Clay Minerals, 29, 113-123.

Inoue A., Bouchet A., Velde B. \& Meunier A. (1989) A convenient technique to estimate smectite layer percentage in randomly interstratified illite / smectite minerals. Clays and Clay Minerals, 37, 3, 227-234.

Lagaly G. \& Weiss A. (1969) Determination of the layer charge in mica-type layer silicates. Pp 61-80 in Proceedings, International Clay Conference, Tokyo, Japan, 1.

Lanson B. (1997) Decomposition of experimental X-ray diffraction patterns (profile fitting): a convenient way to study clay minerals. Clays and Clay Minerals, 45, 132-146.

Meunier A., Proust D. \& Moreau P. (1999) Geological significance of two smectiterich beds from Lower Cenomanian sediments, northern Aquitaine basin, France. Bulletin de la Société Géologique de France, 170, 873-882.

Meunier A., Lanson B. \& Beaufort D. (2000) Vermiculitization of smectite interfaces and illite layer growth as a possible dual model for illite-smectite illitization in diagenetic environments: a synthesis. Clay Minerals, 35, 573-586.

Moore D. M. \& Reynolds R. C. (1989) X-ray diffraction and the identification and analysis of clay minerals. Oxford University Press, Oxford. 
Olis A.C., Malla P.B. \& Douglas L.A. (1990) The rapid estimation of the layer charges of 2:1 expanding clays from a single alkylammonium ion expansion. Clay Minerals, 25, 39-50.

Plançon A. \& Drits V.A. (2000) Phase analysis of clays using an expert system and calculation programs for X-ray diffraction by two- and three-component mixedlayer minerals. Clays and Clay Minerals, 48, 57-62.

Sakharov B.A., Lindgreen H., Salyn A.L. \& Drits V.A. (1999) Determination of illitesmectite structures using multispecimen X-ray diffraction profile fitting. Clays and Clay Minerals, 40, 103-113.

Srodon J. (1981) X-ray identification of randomly interstratified illite-smectite in mixtures with discrete illite. Clay Minerals, 16, 297-304.

Sucha V., Kraus I., Gerthofferova H., Petes J. \& Serekova M. (1993) Smectite to illite conversion in bentonites and shales of the East Slovak basin. Clay Minerals, 28, 243-253.

Velde B. \& Brusewitz A.M. (1982) Metasomatic and non-metasomatic low-grade metamorphism of Ordovician meta-bentonites in Sweden. Geochimica et Cosmochimica Acta, 46, 446-452.

Velde B., Suzuki T. \& Nicot E. (1986) Pressure-temperature-composition of illite/smectite mixed-layer minerals: Niger delta mudstones and other examples. Clays and Clay Minerals, 34, 435-441.

Watanabe T. (1988) The structural model of illite/smectite interstratified minerals and the diagram for their identification. Clay Science, 7, 97-114.

Weir, A.H., Ormerod, E.G. \& El Mansey, I.M.I. (1975) Clay mineralogy of sediments of the western Nile Delta. Clay Minerals, 10, 369-386. 


\section{FIGURE CAPTIONS}

FIG. 1. Geological settings. a) Location of the Archingeay quarry (AHY) in the Cenomanian formations of the northern part of the Aquitaine basin. b) Geologic sequence and sampling of the bentonite bed (A to E).

FIG. 2. XRD patterns calculated for randomly interstratified illite-expandable (I-Exp) mixed-layer minerals (MLMs). The proportion of expandable layers (80\%) is constant for all patterns but the swelling behavior is modified. From top to bottom the relative proportion of expandable layers accepting two sheets of ethylene glycol (EG) molecules in their interlayers (S-type layers) increases 50-80\%. Structural parameters (ion position, d-spacings) used for the calculation are those recommended by Moore \& Reynolds (1989). Arrows indicate the shift of peak position resulting from the heterogeneous swelling behavior of expandable layers.

FIG. 3. Variation of the $\mathrm{Na}_{2} \mathrm{O}+\mathrm{CaO}$ amounts (a) and the CEC (cmol.kg-1) (b) from the edge (A) to center (E) of the bentonite bed.

FIG. 4. XRD patterns of oriented preparations from the Ca-saturated samples in the ethylene glycol saturated state (EG). Detail of the XRD patterns in the $8-12{ }^{\circ} 2 \theta$ $\mathrm{Cu}-\mathrm{K} \alpha$ angular range. The positions of the (002) diffraction peaks remain constant while their shape and intensity vary with depth.

FIG. 5. XRD patterns of oriented preparations from the Ca-saturated samples in the air-dried state (AD). Detail of the XRD patterns in the $15-20^{\circ} 2 \theta \mathrm{Cu}-\mathrm{K} \alpha$ angular range. The positions of the (003) diffraction peaks remain constant while their shape and intensity vary with depth.

FIG. 6. XRD patterns from Ca-saturated EG samples. Decomposition of the $8-12{ }^{\circ} 2 \theta$ $\mathrm{Cu}-\mathrm{K} \alpha$ angular range. 
FIG. 7. XRD patterns from Ca-saturated AD samples. Decomposition of the $15-20{ }^{\circ} 2 \theta$ $\mathrm{Cu}-\mathrm{K} \alpha$ angular range.

FIG. 8. Calculated XRD patterns from sample D in the Ca-saturated EG state (heavy line curve) based on the two mixed layer components determined by the decomposition of the $8-12^{\circ} 2 \theta \mathrm{Cu}-\mathrm{K} \alpha$ region). The crosses correspond to experimental pattern. Mica and kaolinite contributions were calculated but are not included in the figure for simplicity.

FIG. 9. XRD patterns from oriented mounts in which the octahedral charge has been neutralized using the Hofmann-Klemen treatment.

FIG. 10. XRD patterns from oriented preparations of K-saturated samples in the EG state.

FIG. 11. XRD patterns from K-saturated EG samples. Decomposition of the $2-12{ }^{\circ} 2 \theta$ $\mathrm{Cu}-\mathrm{K} \alpha$ angular range.

FIG. 12. XRD patterns from $\mathrm{C}_{12}$-alkylammonium-saturated samples (Co-K $\left.\alpha\right)$ in which the octahedral charge has been previously neutralized using the Hofmann-Klemen treatment.

FIG. 13. XRD patterns from Li-saturated samples heated to $300^{\circ} \mathrm{C}$ and saturated with a $\mathrm{C}_{12}$ alkylammonium. Decomposition of the $3-12{ }^{\circ} 2 \theta \mathrm{Co}-\mathrm{K} \alpha$ angular range.

FIG. 14. Variation of the position of the most intense band in decomposed XRD patterns from K-saturated samples with depth. The lower the position, the higher the high-charge layer amount (see text for details). 


\section{TABLE CAPTIONS}

TABLE 1. Comparison of the results given by different identification methods from saddle/peak ratio or peak positions of calculated XRD patterns of three component mixed layers minerals. NA: not analyzed. (See text for details).

TABLE 2. Chemical composition and Cation Exchange Capacity (CEC) of the $<2 \mu \mathrm{m}$ fraction of smectite collected at several points in the bentonite layer.

TABLE 3. Decomposition values of XRD patterns (8 to $12^{\circ} 2 \theta \mathrm{Cu}-\mathrm{K} \alpha$ angular range) of bentonite samples in the Ca-saturated EG state.

TABLE 4. Decomposition values of XRD patterns (15 to $20^{\circ} 2 \theta \mathrm{Cu}-\mathrm{K} \alpha$ angular range) of bentonite samples in the Ca-saturated AD state. 
TABLE 1

\begin{tabular}{|c|c|c|c|c|c|c|c|}
\hline \multicolumn{2}{|c|}{${ }^{2} \mathrm{I}_{20 \%}-\operatorname{Exp}_{80 \%}$} & \multicolumn{5}{|c|}{ Peak position $\left({ }^{\circ} 2 \theta \mathrm{Cu}-\mathrm{K} \alpha\right)$} & \multirow{2}{*}{$\begin{array}{c}\text { Identification } \\
\text { Srodon } \\
(1981)\end{array}$} \\
\hline${ }^{3} \mathrm{~S} \%$ & ${ }^{4} \mathrm{~V} \%$ & ${ }^{1} 001$ & ${ }^{1} 002$ & ${ }^{1} 003$ & ${ }^{1} 005$ & ${ }^{1} 006$ & \\
\hline \multirow[t]{2}{*}{80} & \multirow[t]{2}{*}{0} & 5.11 & 9.96 & 15.73 & 26.40 & 31.75 & \multirow{2}{*}{$90 \% \mathrm{~S}$} \\
\hline & & $17.3 \AA$ & $8.88 \AA$ & $5.63 \AA$ & $3.376 \AA$ & $2.818 \AA$ & \\
\hline \multirow[t]{2}{*}{70} & \multirow[t]{2}{*}{10} & 5.18 & 9.89 & 15.69 & 26.48 & 31.74 & \multirow{2}{*}{$95 \% \mathrm{~S}$} \\
\hline & & $17.0 \AA$ & $8.94 \AA$ & $5.65 \AA$ & $3.366 \AA$ & $2.819 \AA$ & \\
\hline \multirow[t]{2}{*}{60} & \multirow[t]{2}{*}{20} & 5.28 & 9.77 & 15.62 & 26.59 & 31.73 & \multirow{2}{*}{ NA } \\
\hline & & $16.7 \AA$ & $9.05 \AA$ & $5.67 \AA$ & $3.352 \AA$ & $2.820 \AA$ & \\
\hline \multirow[t]{2}{*}{50} & \multirow[t]{2}{*}{30} & 5.40 & 9.33 & 15.54 & 26.73 & 31.69 & \multirow{2}{*}{ NA } \\
\hline & & $16.4 \AA$ & $9.48 \AA$ & $5.70 \AA$ & $3.335 \AA$ & $2.823 \AA$ & \\
\hline
\end{tabular}

${ }^{1}$ Peaks are labeled as smectite; ${ }^{2}$ randomly ordered illite/smectite mixed layer mineral; ${ }^{3} \mathrm{~S}$ : smectite (2 EG sheets), ${ }^{4} \mathrm{~V}$ : vermiculite (1 EG sheet).

\begin{tabular}{cccccc}
\multicolumn{2}{c}{$\mathrm{I}_{20 \%}$-Exp80\% } & & & \multicolumn{2}{c}{ Identification } \\
\hline S\% & V\% & $\begin{array}{c}\text { Peak } \\
\text { position }\end{array}$ & $\begin{array}{c}\text { Saddle/pea } \\
\text { k ratio }\end{array}$ & $\begin{array}{c}\text { Inoue et al. } \\
(1989)\end{array}$ & $\begin{array}{c}\text { Weir et al. } \\
(1975)\end{array}$ \\
\hline 80 & 0 & 5.11 & 0.38 & $72 \%$ & $82 \%$ \\
70 & 10 & 5.18 & & & \\
& & $17.3 \AA$ & 0.45 & $67 \%$ & $78 \%$ \\
60 & 20 & 5.28 & & & $74 \%$ \\
& & $16.7 \AA$ & 0.53 & $62 \%$ & $72 \%$ \\
\hline
\end{tabular}


TABLE 2

\begin{tabular}{cccccc}
\hline Sample & $\mathbf{A}$ & $\mathbf{B}$ & $\mathbf{C}$ & $\mathbf{D}$ & $\mathbf{E}$ \\
\hline $\begin{array}{c}\text { Sampling } \\
\text { depth (cm) }\end{array}$ & 10 & 20 & 30 & 40 & 50 \\
\hline $\mathrm{SiO}_{2}$ & 57.78 & 57.03 & 56.36 & 62.22 & 57.08 \\
$\mathrm{Al}_{2} \mathrm{O}_{3}$ & 15.63 & 16.04 & 16.09 & 14.41 & 15.82 \\
$\mathrm{Fe}_{2} \mathrm{O}_{3}$ & 4.46 & 5.37 & 5.00 & 4.13 & 3.91 \\
$\mathrm{MgO}$ & 1.99 & 2.03 & 1.95 & 1.67 & 1.74 \\
$\mathrm{TiO}_{2}$ & 0.82 & 0.85 & 0.96 & 0.84 & 0.88 \\
$\mathrm{MnO}_{\mathrm{CaO}}$ & 0.01 & 0.01 & 0.01 & 0.01 & 0.01 \\
$\mathrm{Na}_{2} \mathrm{O}$ & 3.35 & 2.18 & 1.44 & 1.40 & 1.16 \\
$\mathrm{~K}_{2} \mathrm{O}$ & 0.31 & 0.23 & 0.18 & 0.16 & 0.11 \\
$\mathrm{CEC}$ & 1.31 & 1.31 & 1.29 & 1.36 & 1.29 \\
$\left(\mathrm{cmol.kg}{ }^{-1}\right)$ & 79.8 & 78.8 & 76.3 & 75.7 & 74.1 \\
\hline
\end{tabular}

TABLE 3

\begin{tabular}{|c|c|c|c|c|c|c|c|c|c|}
\hline \multirow{2}{*}{ Sample } & \multicolumn{3}{|c|}{${ }^{1}$ I-Exp 1} & \multicolumn{3}{|c|}{${ }^{1}$ I-Exp2 } & \multicolumn{3}{|c|}{ Illite } \\
\hline & ${ }^{2}$ Pos. $(\AA)$ & Intensity & ${ }^{3} \mathrm{FWHM}$ & ${ }^{2}$ Pos. (Å) & Intensity & ${ }^{3} \mathrm{FWHM}$ & ${ }^{2}$ Pos. ( $\left.\AA\right)$ & Intensity & ${ }^{3} \mathrm{FWHM}$ \\
\hline A & 8.52 & 397 & 0.76 & 9.26 & 216 & 1.46 & 9.96 & 217 & 0.22 \\
\hline B & 8.52 & 559 & 0.78 & 9.23 & 275 & 1.26 & 9.99 & 209 & 0.38 \\
\hline C & 8.49 & 315 & 0.72 & 8.97 & 153 & 0.70 & 10.02 & 128 & 0.29 \\
\hline D & 8.43 & 204 & 0.59 & 8.75 & 276 & 1.03 & 10.02 & 272 & 0.50 \\
\hline $\mathbf{E}$ & 8.47 & 113 & 0.67 & 8.72 & 93 & 1.11 & 10.02 & 318 & 0.30 \\
\hline
\end{tabular}

${ }^{1} \mathrm{I} / \mathrm{S}$ MLMs ; ${ }^{2}$ peak position ; ${ }^{3}$ Full Width at Half Maximum intensity 
TABLE 4

\begin{tabular}{cccccccccc}
\hline \multirow{2}{*}{ Sample } & \multicolumn{3}{c}{${ }^{1}$ I-Exp $_{1} \pm$ Illite } & \multicolumn{3}{c}{${ }^{1}$ I-Exp $_{2}$} & \multicolumn{3}{c}{ Illite } \\
& ${ }^{2}$ Pos. $(\AA)$ & Intensity & ${ }^{3}$ FWHM & ${ }^{2}$ Pos. $(\AA)$ & Intensity & ${ }^{3}$ FWHM & ${ }^{2}$ Pos. $(\AA)$ & Intensity & ${ }^{3}$ FWHM \\
\hline A & 4.99 & 249 & 0.57 & 5.03 & 368 & 1.47 & 4.95 & 189 & 0.17 \\
B & 5.00 & 329 & 0.74 & 5.04 & 366 & 1.62 & 4.96 & 251 & 0.20 \\
C & 5.03 & 581 & 0.95 & 5.07 & 616 & 1.89 & 4.99 & 364 & 0.36 \\
D & 5.00 & 515 & 0.74 & 5.07 & 631 & 1.71 & 4.97 & 344 & 0.19 \\
E & 5.00 & 393 & 0.67 & 5.06 & 446 & 1.72 & 4.97 & 339 & 0.17 \\
\hline
\end{tabular}

${ }^{1}$ I/S MLMs ; ${ }^{2}$ peak position ; ${ }^{3}$ Full Width at Half Maximum intensity 


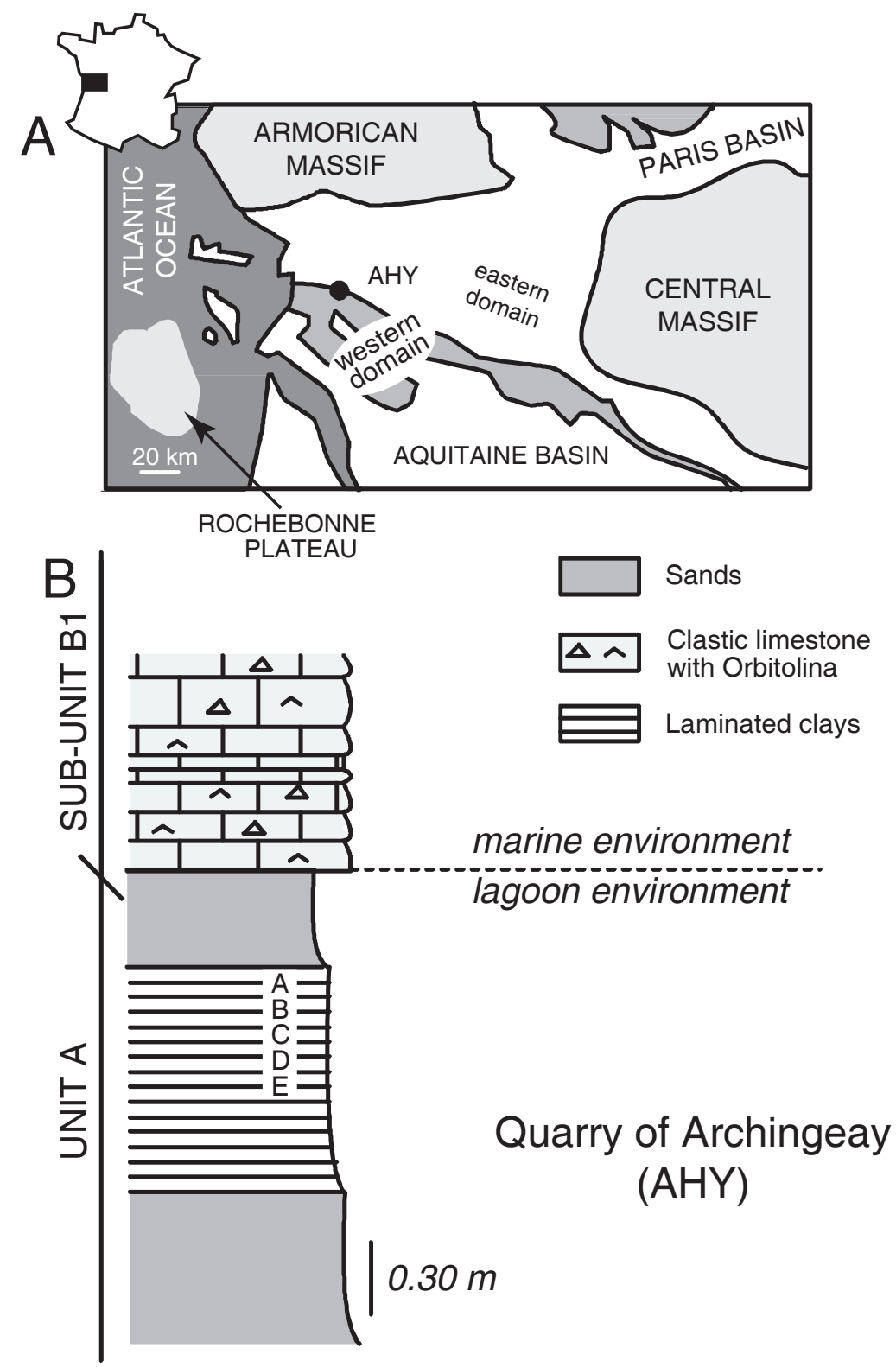




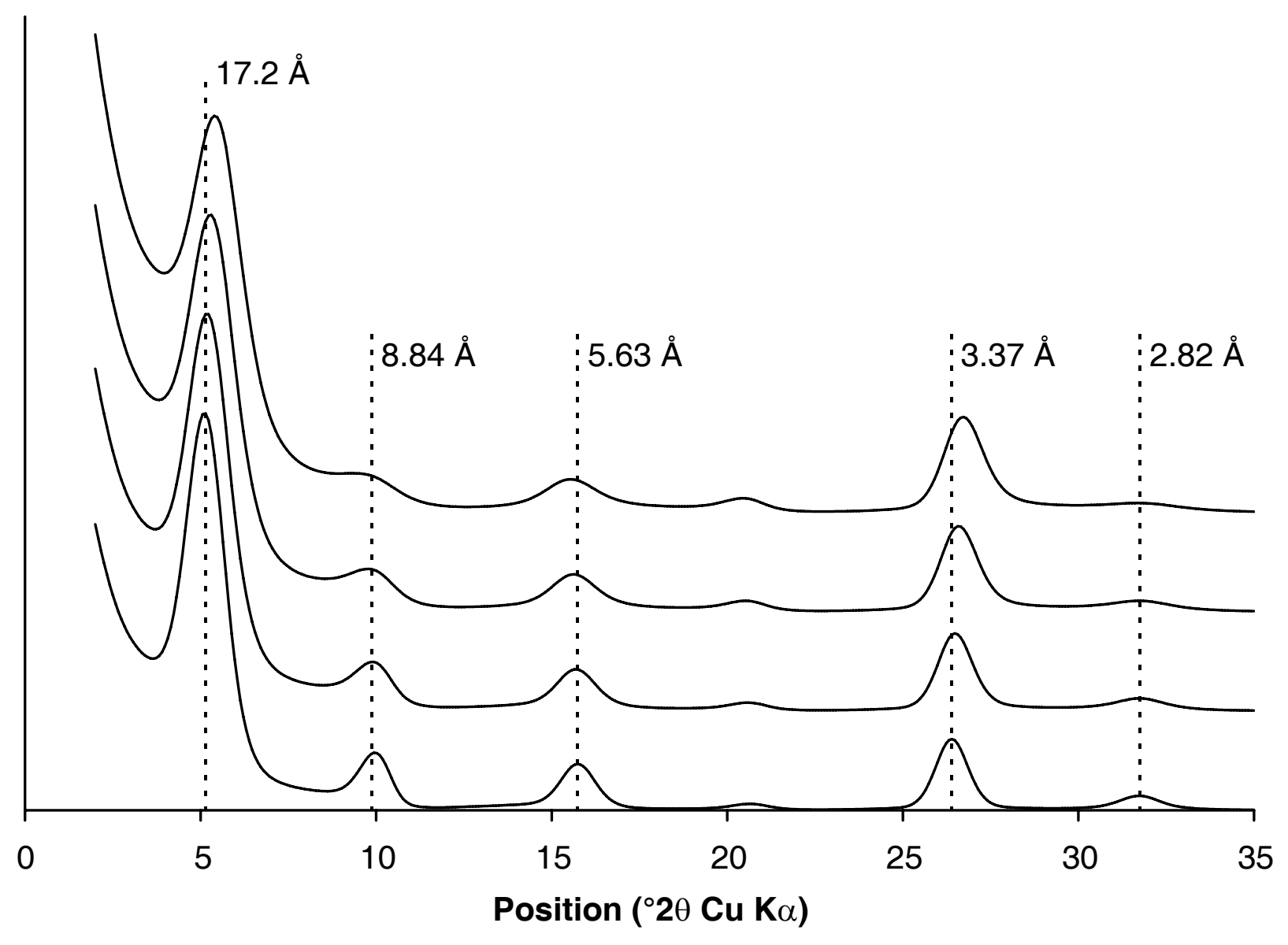



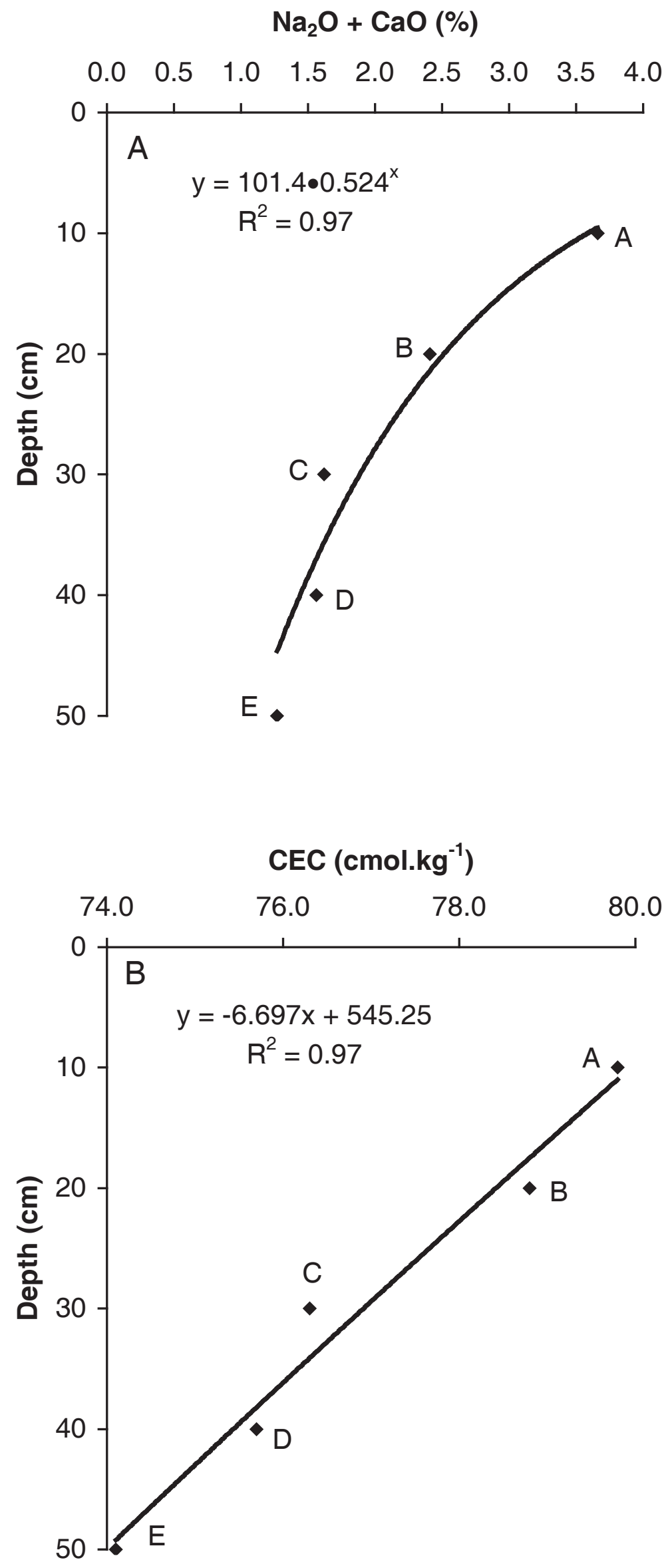


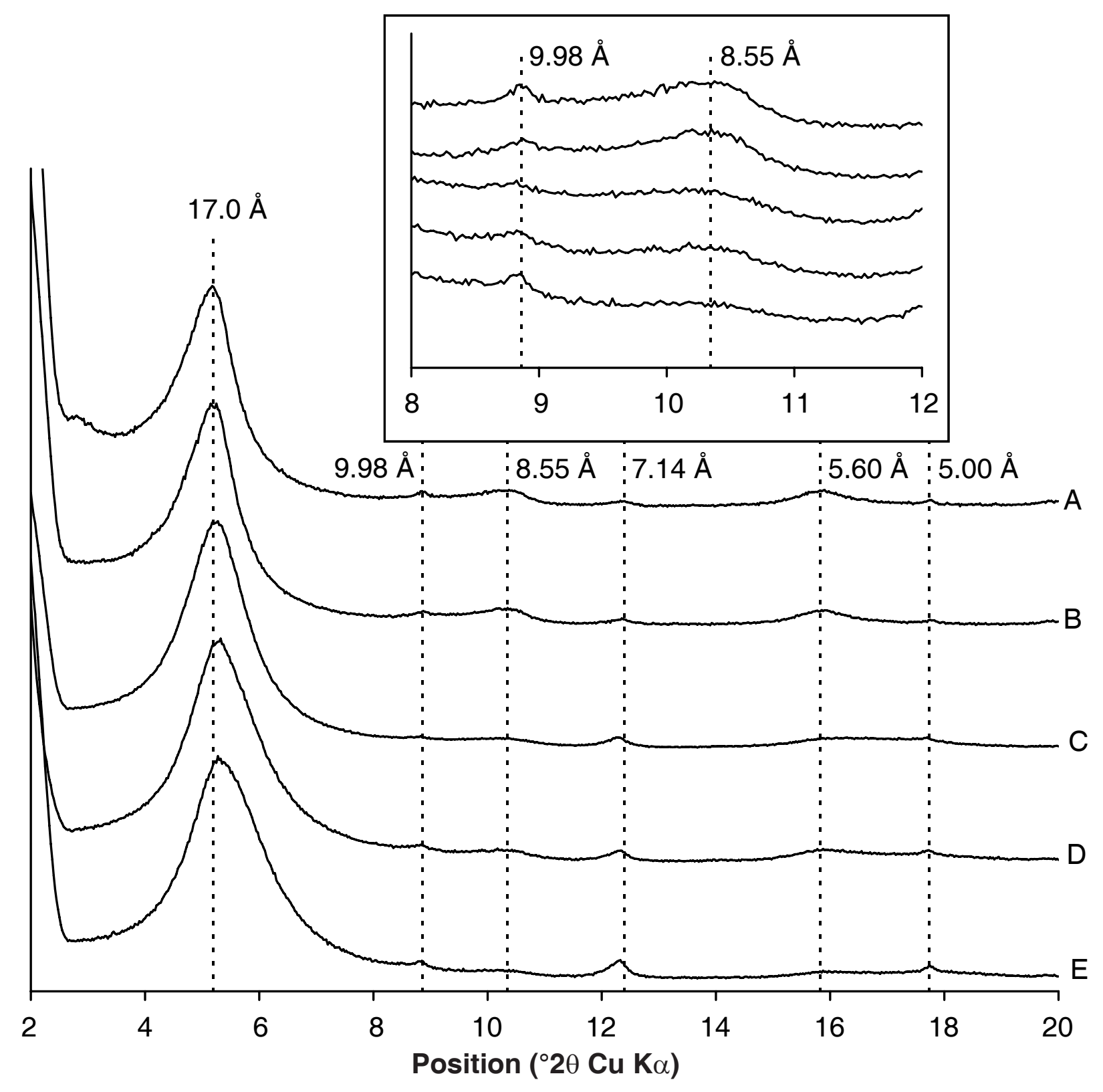




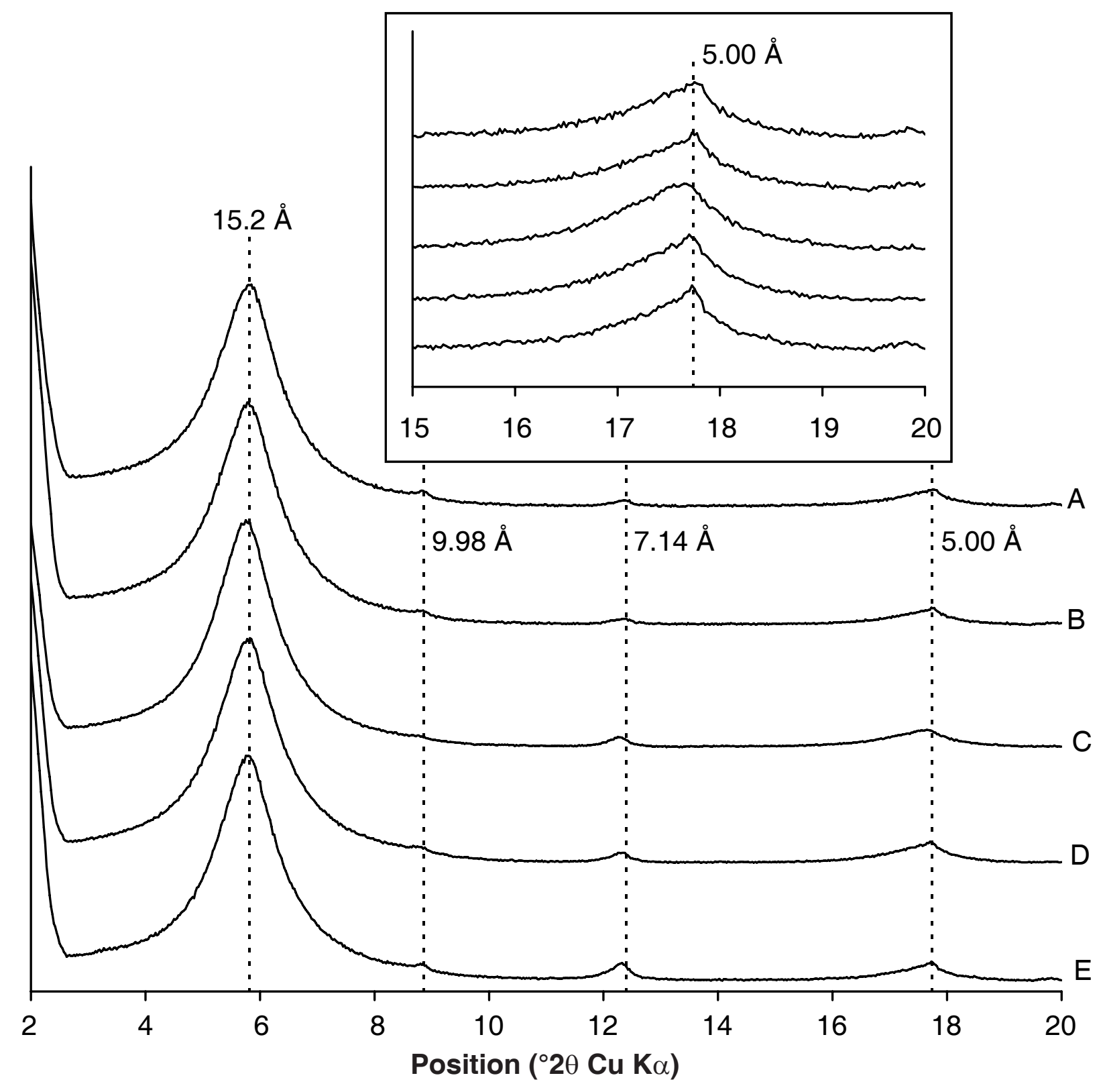



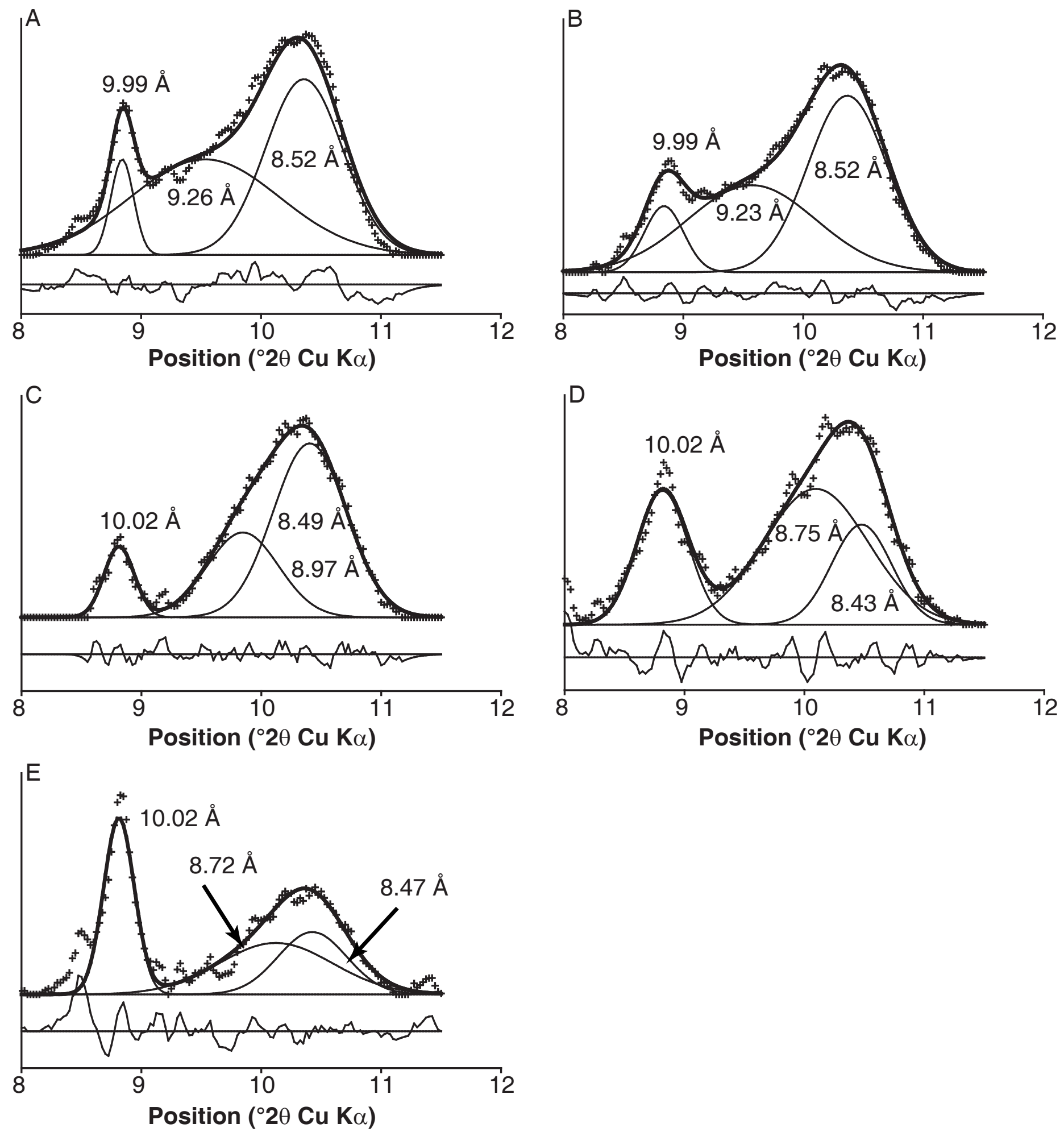

Meunier et al. Fig. 06 

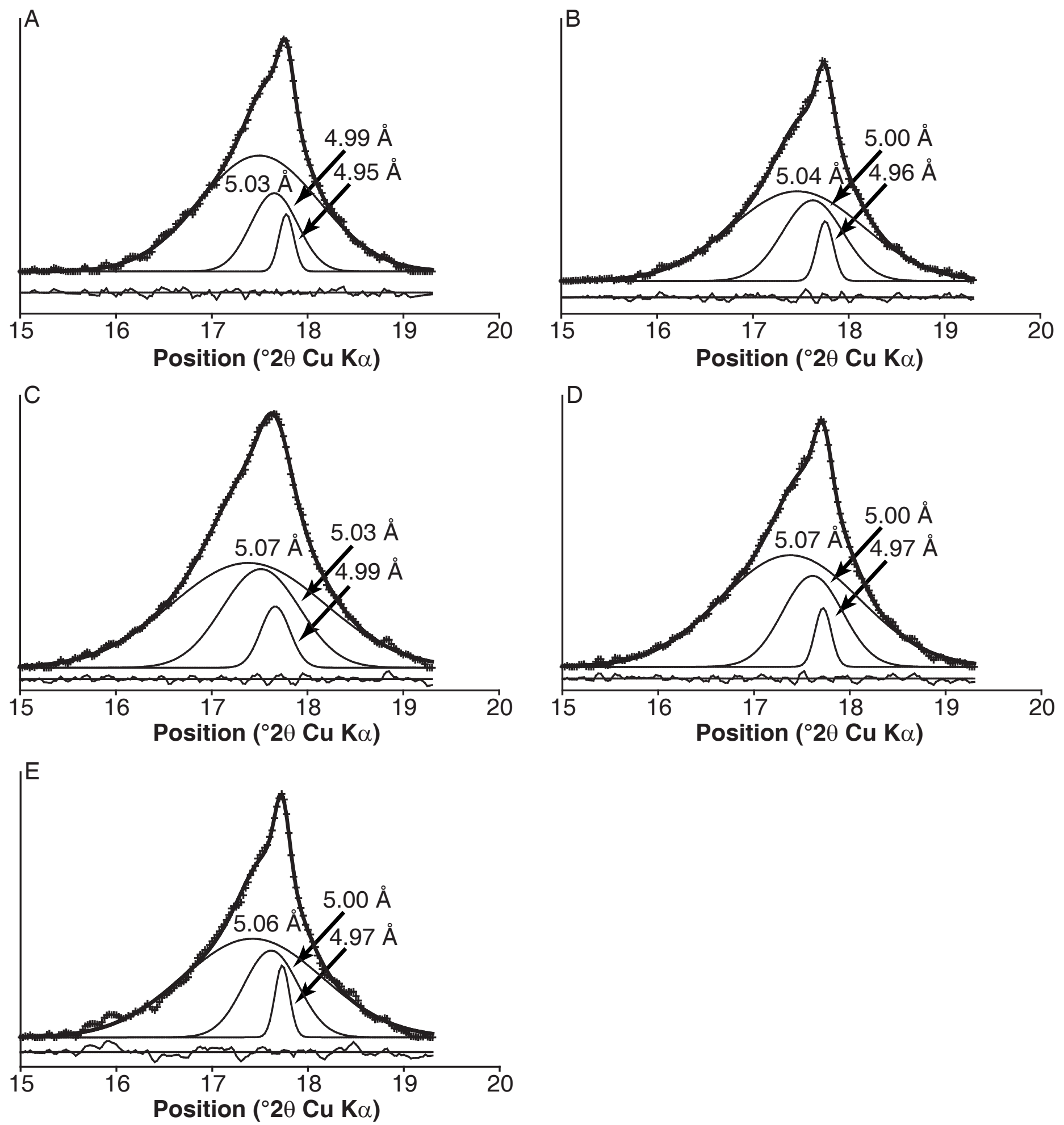


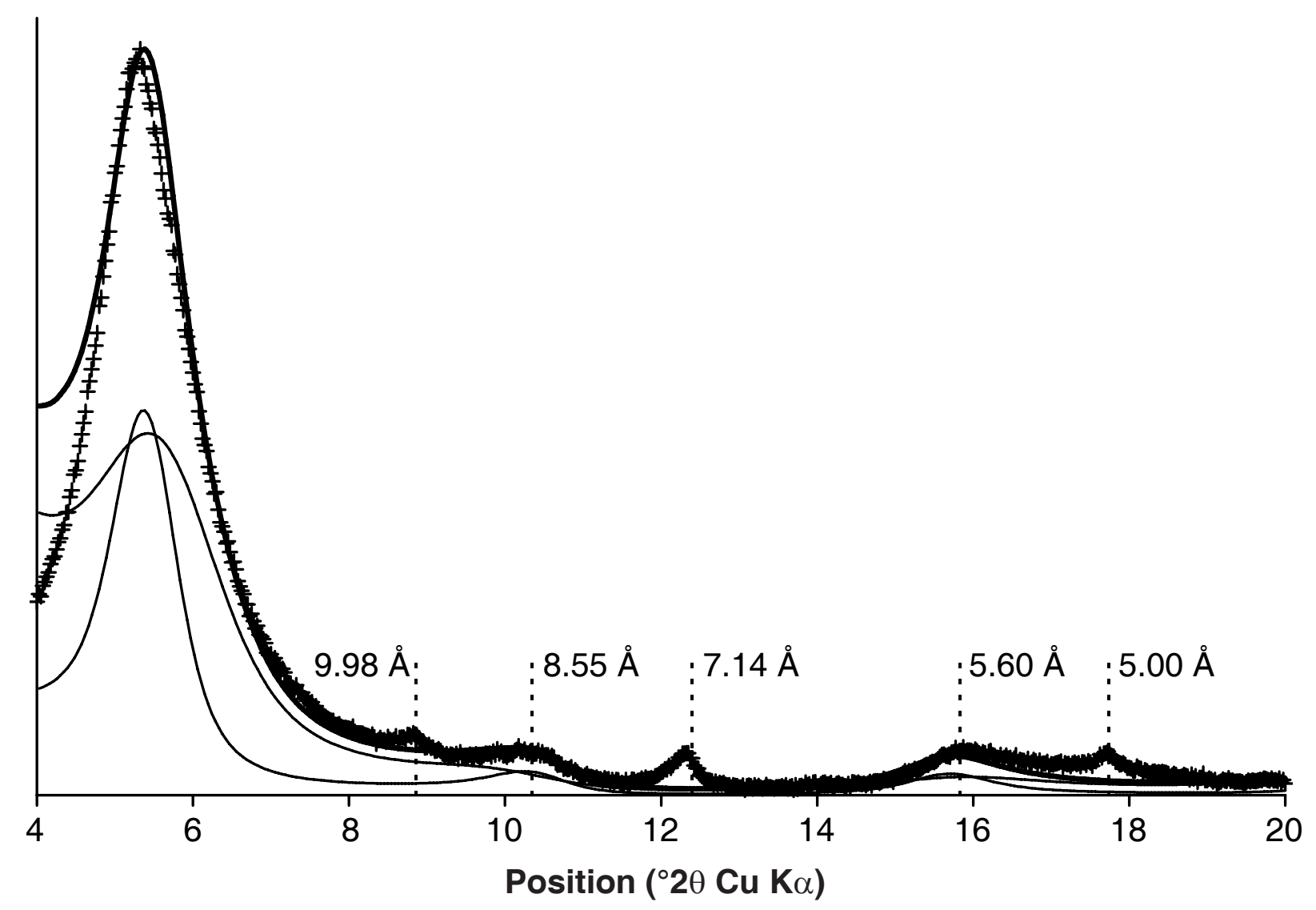




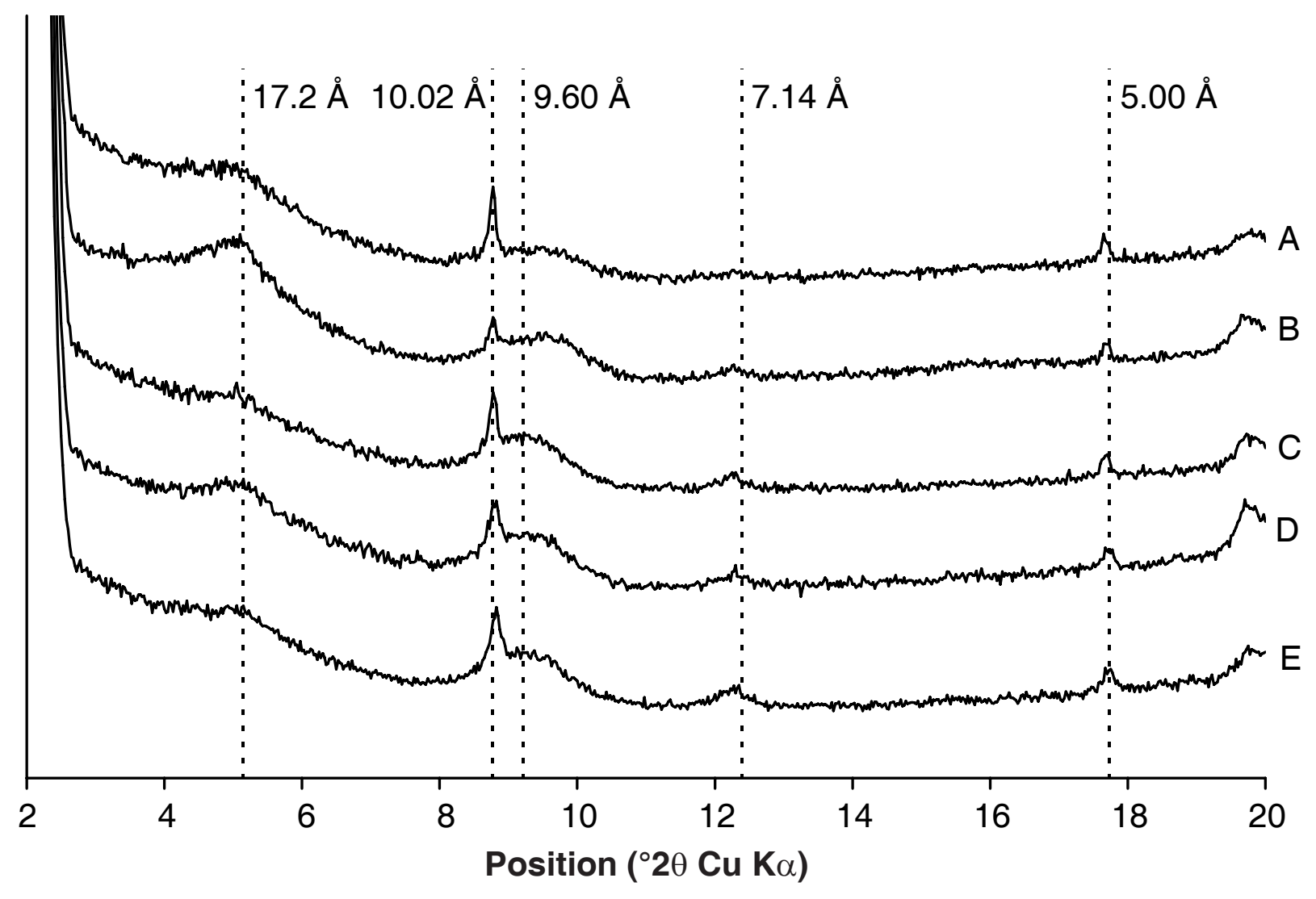

Meunier et al., Fig. 09 


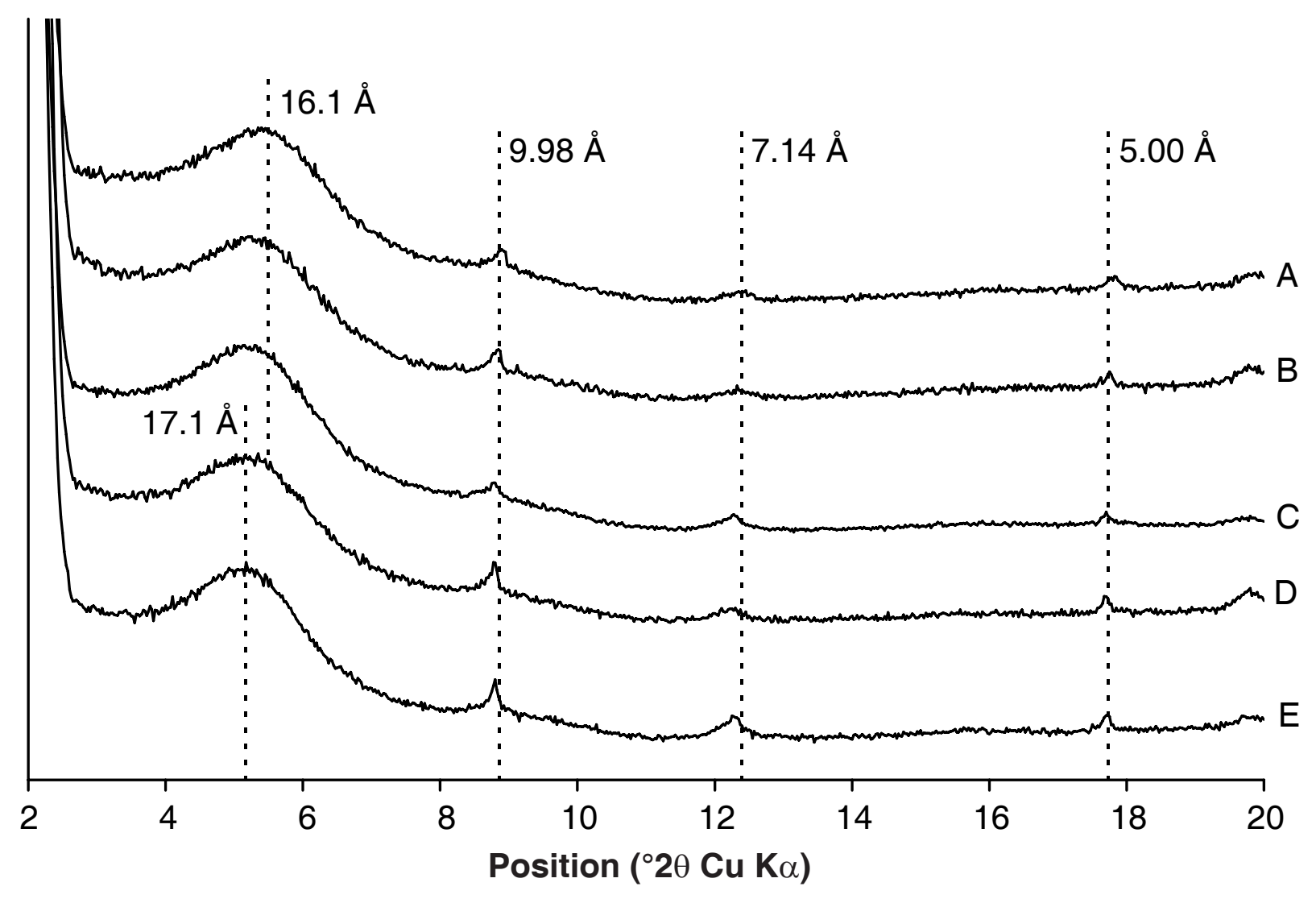

Meunier et al., Fig. 10 

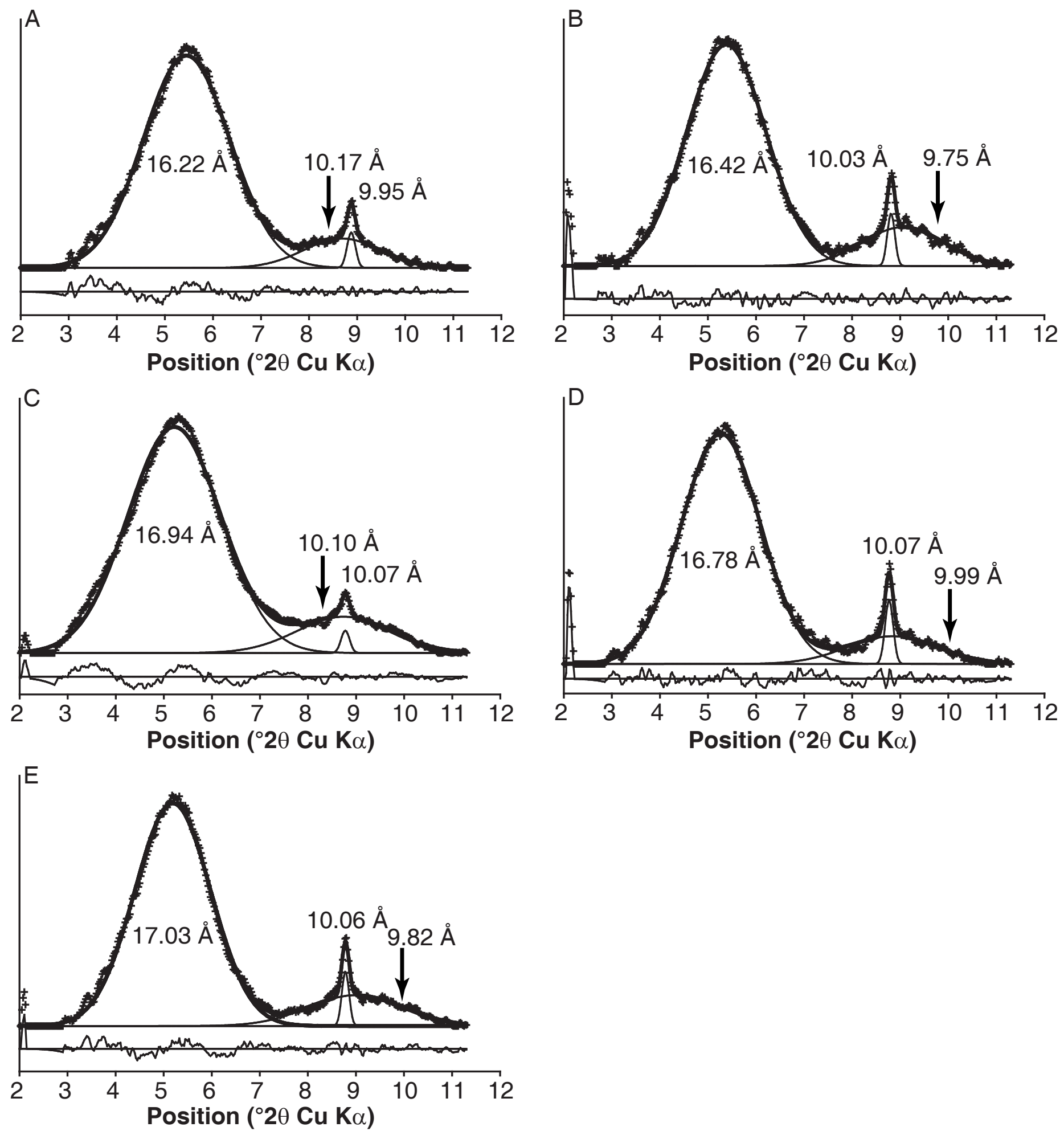


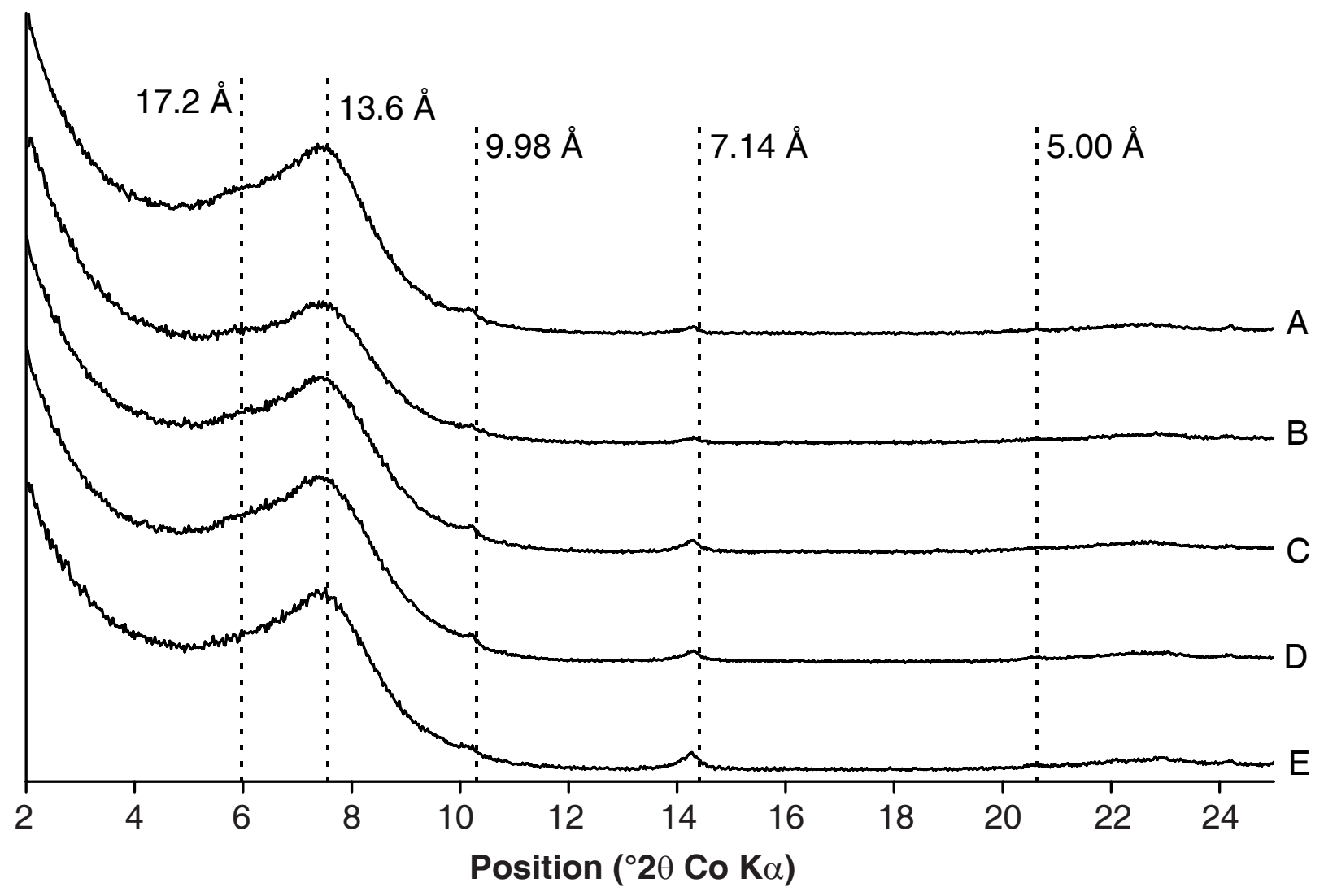



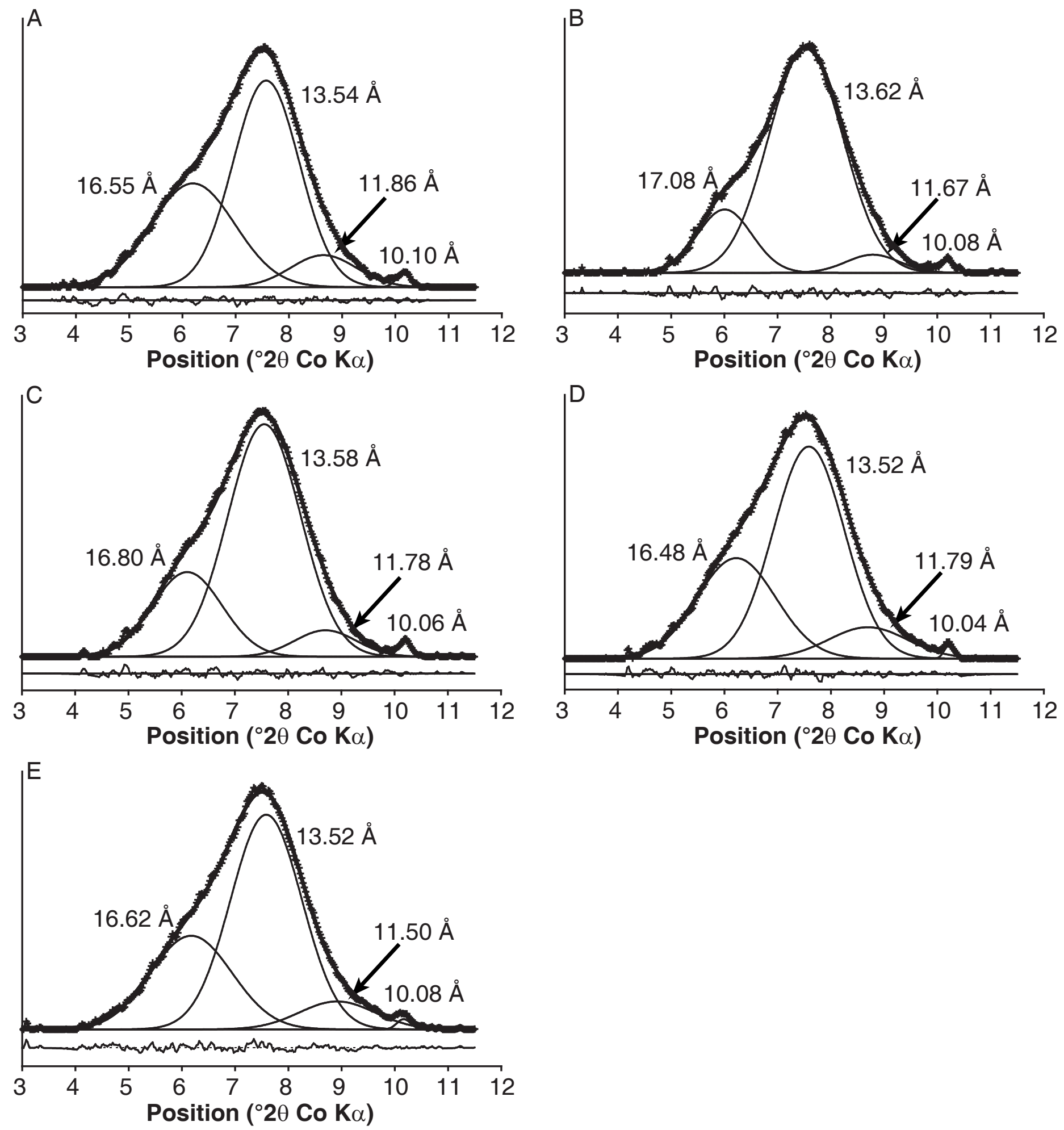


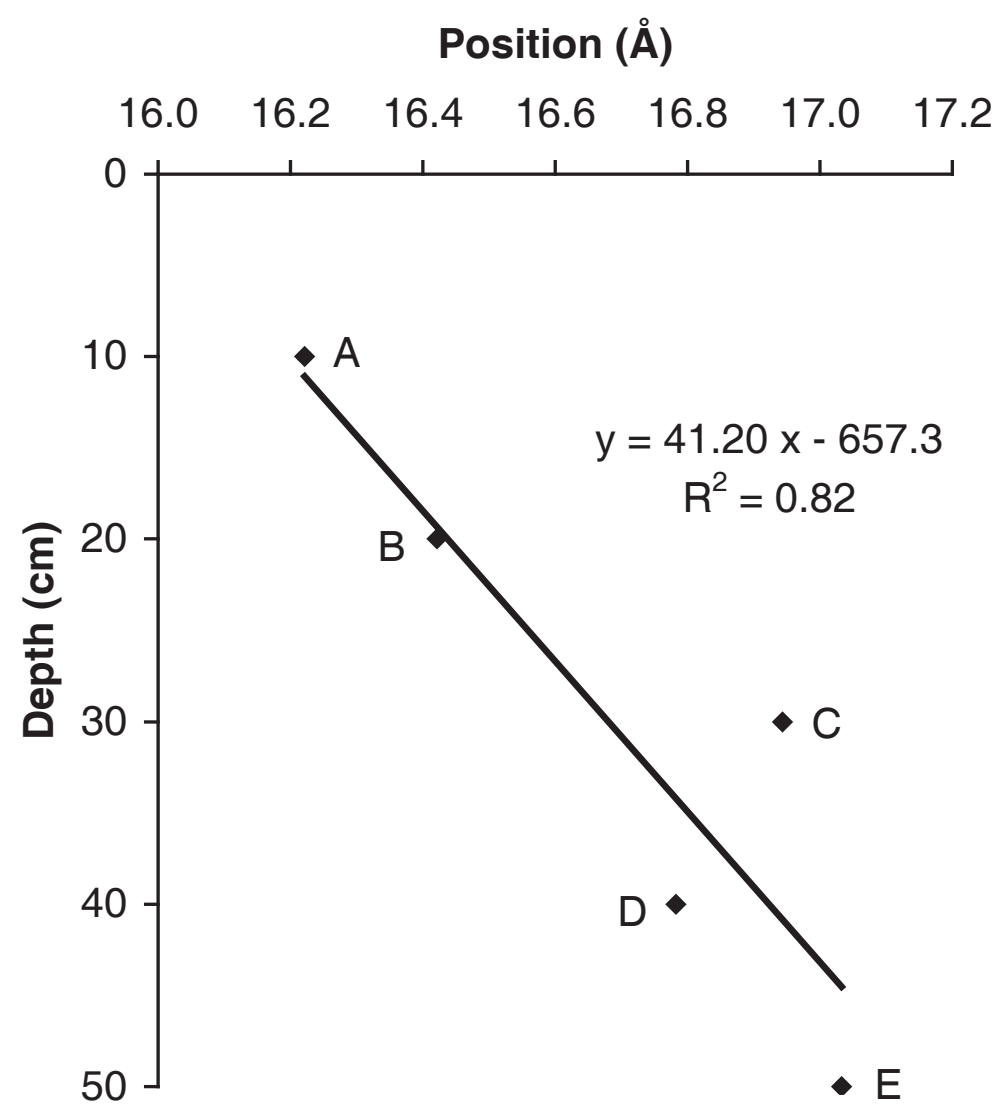

